\title{
Nitrogen Sources Inhibit Biofilm Formation by Xanthomonas oryzae pv. oryzae ${ }^{\mathbb{S}}$
}

\author{
Youngseok Ham and Tae-Jong Kim* \\ Department of Forest Products and Biotechnology, College of Science and Technology, Kookmin University, Seoul 02707, Republic of Korea
}

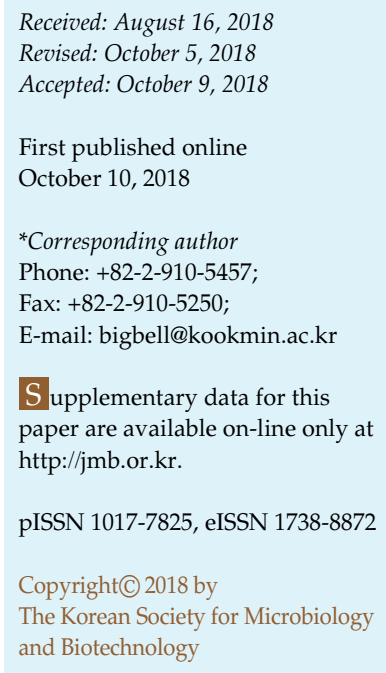

Xanthomonas oryzae pv. oryzae (Xoo) causes bacterial blight, which results in severe economic damage to rice farms. Xoo produces biofilms for pathogenesis and survival both inside and outside the host. Biofilms, which are important virulence factors, play a key role in causing the symptoms of Xoo infection. In the present study, we investigated the nutritional conditions for biofilm formation by Xoo. Although Xoo biofilm formation may be initiated by interactions with the host, Xoo biofilm cannot mature without the support of favorable nutritional conditions. Nitrogen sources inhibited Xoo biofilm formation by overwhelming the positive effect that cell growth has on it. However, limited nutrients with low amino acid concentration supported biofilm formation by Xoo in the xylem sap rather than in the phloem sap of rice.

Keywords: Xanthomonas oryzae pv. oryzae, biofilm, nitrogen source, rice, xylem

\section{Introduction}

Xanthomonas oryzae pv. oryzae (Xoo) is the causative agent of bacterial blight in rice [1], which is the second most cultivated crop worldwide. Bacterial blight may cause losses of up to $32 \%$ of rice yields, depending on the rice cultivar and environmental conditions [2]. The natural habitat of Xoo has not yet been completely defined, but several potential habitats have been suggested [3,4]. The two primary potential habitats of Xoo are seeds and the natural environment. It has been previously demonstrated that rice seeds may carry live Xoo cells [5]; however, whether Xoo carried by seeds causes bacterial blight is a subject of debate $[6,7]$. In the natural environment, Xoo survival depends upon conditions surrounding the cells [8, 9]. Biofilm formation by Xoo is pivotal not only for the survival of the bacteria but also for its persistence in the environment.

A biofilm provides a protective niche for bacteria $[10,11]$. Surrounded by a biofilm, bacteria change their gene expression and eventually become more resistant to hostile environmental conditions [12, 13]. Xoo is a good biofilm producer [14]; in addition to increased survivability, biofilm formation has been suggested to be involved in Xoo pathogenesis $[15,16]$. Xoo enters rice by withdrawing guttation fluid $[17,18]$ or by traveling through wounds or sheath openings [18]. After reaching the xylem, Xoo propagates [19], activates rice defense systems [20], thickens the secondary wall [21], and increases cationic peroxidase levels [22]. Eventually, the aggregation of cells and their exopolysaccharides form a biofilm that blocks the rice vessels [23, 24]. In rice, Xoo preferentially forms a biofilm in the xylem rather than in the phloem. In order to understand Xoo pathogenesis and its biofilm formation in rice, it is essential to identify the nutritional conditions that promote biofilm formation by Xoo.

\section{Materials and Methods}

\section{Bacterial Strain and Growth Conditions}

X. oryzae pv. oryzae (KACC 10331) was used in the present study. The Xoo genome has been completely sequenced [25], making this strain a good model for further molecular biology studies. Minimal medium [26], 210 medium [27], nutrient broth (BD, Franklin Lakes, NJ), PS medium [28], SOC medium [29], 
XOM2 medium [30], and MME medium [31] were prepared, according to previous studies or the manufacturer's instructions. The detailed compositions of media were listed in Tables S1 to S7. The amino acid compositions of xylem [32] and phloem [33] saps in XOM2 medium were made according to previous studies. The detailed compositions of media were listed in Tables S8 and S9, respectively.

\section{Measuring Cell Numbers}

For cell number analysis, Xoo was subcultured to an absorbance of 0.05 at $600 \mathrm{~nm}\left(\mathrm{Abs}_{600}\right)$ in $100 \mathrm{ml}$ of 210 medium in 250-ml baffled flasks and incubated at $28^{\circ} \mathrm{C}$ and $250 \times g$ for $48 \mathrm{~h}$. The growth of Xoo was measured as $\mathrm{Abs}_{600}$, and the colony-forming units (CFUs) were calculated using a conversion factor of $1.12 \times 10^{9} \mathrm{CFU} / \mathrm{Abs}_{600}$.

\section{Biofilm Formation and Quantitative Analysis Using Crystal Violet}

Xoo stored as frozen stock at $-80^{\circ} \mathrm{C}$ was grown on YGC agar plates $\left(50 \mathrm{~g} / 1\right.$ glucose, $5 \mathrm{~g} / 1$ yeast extract, $12.5 \mathrm{~g} / 1 \mathrm{CaCO}_{3}$, and $15 \mathrm{~g} / \mathrm{l}$ agar) at $28^{\circ} \mathrm{C}$ for $48 \mathrm{~h}$. Five milliliters of 210 medium was inoculated with $\mathrm{Xoo}$ and incubated at $28^{\circ} \mathrm{C}$ and $250 \times g$ for $48 \mathrm{~h}$. For the biofilm assays, Xoo was subcultured to an $\mathrm{Abs}_{600}$ of 0.05 in $100 \mu \mathrm{l}$ of each medium indicated above in 96-well polyvinyl chloride (PVC) microplates. Cultures were incubated at $28^{\circ} \mathrm{C}$ for $24 \mathrm{~h}$. Biofilms were quantified via the crystal violet assay, as previously described [34]. After cell culture in 96-well PVC microplates, excess cells were removed and the wells were rinsed three times with double-distilled water. Each well was incubated with $100 \mu \mathrm{l}$ of $1 \%$ crystal violet for $15 \mathrm{~min}$ at room temperature. The wells were then rinsed three times with double-distilled water, and $100 \mu \mathrm{l}$ of $95 \%$ ethanol was then added to each well to solubilize the crystal violet. The plates were then incubated for an additional 15 min. An ELx800 microplate reader equipped with KC4 software (Bio-Tek Instruments, Inc., Winooski, VT) was used to measure the absorbance of each well at $595 \mathrm{~nm}$. Uninoculated wells were used as blanks and were subtracted from each value to calculate the final absorbance value at $595 \mathrm{~nm}$.

\section{Results}

\section{Effects of Nutrient Availability on Biofilm Formation}

Biofilm formation by Xoo was evaluated in seven reported media (Fig. 1A). Biofilm formation in complex nutrient-rich media, such as 210 medium, nutrient broth, PS medium, and SOC medium, was minimal; however, biofilm formation in the defined nutrient-limited media, such as XOM2 medium, minimal medium, and MME medium, was considerable. To verify the limitation of bacterial growth in the defined nutrient-limited media, the cell growth in seven reported media was evaluated (Fig. 1B). After $10 \mathrm{~h}$ of incubation, the cell density of the nutrient-rich medium was more than twice that in the nutrient-limited

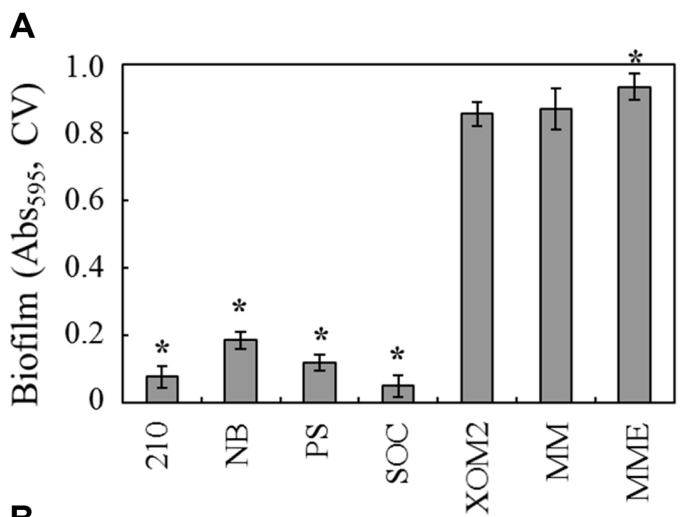

B

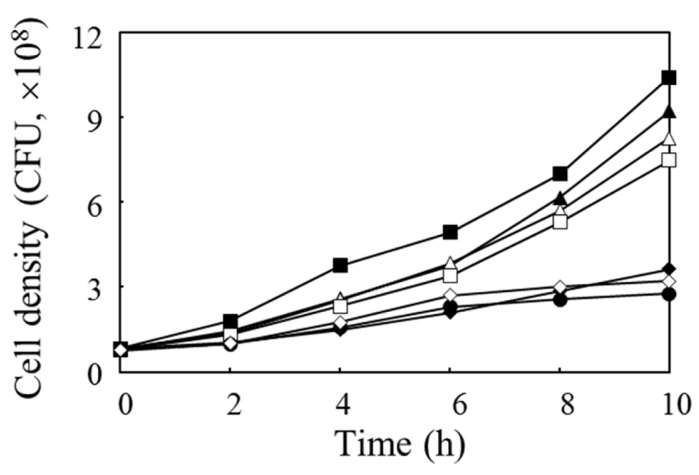

Fig. 1. Effect of media on Xoo biofilm formation and cell growth.

(A) Xoo biofilm formation. Cells were incubated in 96-well polyvinyl chloride microplates for $24 \mathrm{~h}$. Biofilms were quantified using crystal violet (CV in the y-axis label). The media used were 210 medium (210), nutrient broth (NB), PS medium (PS), SOC medium (SOC), XOM2 medium (XOM2), minimal medium (MM), and MME medium (MME). The mean values showing a statistically significant difference in comparison with the value of XOM2 were denoted by * $(p<0.05)$. (B) Xoo cell growth. The colony-forming units were quantified using a conversion factor of $1.12 \times 10^{9} \mathrm{CFU} / \mathrm{Abs}_{600}$. The media used were 210 medium ( $\square$ ), nutrient broth $(\square)$, PS medium ( $\boldsymbol{\Delta}$ ), SOC medium $(\triangle)$, XOM2 medium $(\diamond)$, minimal media $(\diamond)$, and MME medium $(\bullet)$. Data represent mean \pm standard deviation from 6 independent experiments.

medium containing defined nutrients. These results, shown in Figs. 1A and 1B, suggested that growth-limiting conditions supported biofilm formation by Xoo.

\section{Effect of Carbon Source on Biofilm Formation}

In order to determine the nutrient component in the complex media that inhibited biofilm formation by Xoo, eight carbon sources, including those used in the tested complex media listed in Fig. 1, were tested (Fig. 2). The xylose in the XOM2 medium was substituted with the 


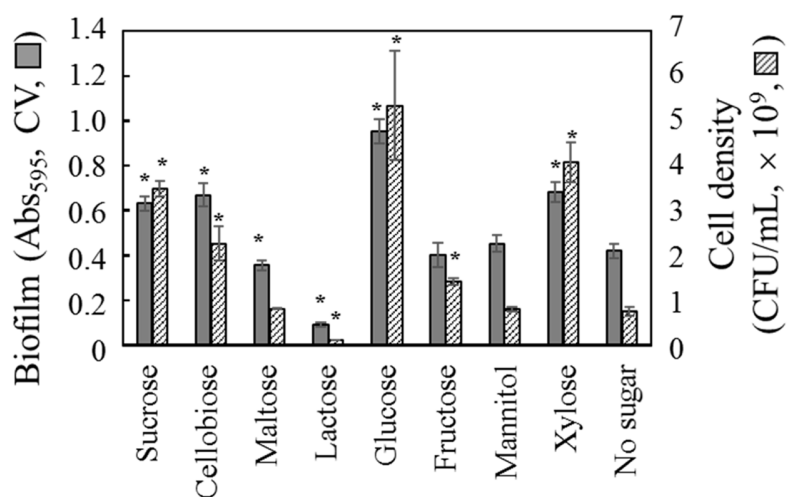

Fig. 2. Effect of carbon sources on Xoo biofilm formation (solid bars) and cell growth (hatched bars).

Cells were incubated in 96-well polyvinyl chloride microplates for $24 \mathrm{~h}$ with XOM2 medium in which xylose was replaced with $0.18 \%$ of the indicated carbon sources. The cell growth was measured independently by culturing cells in test tubes (hatched bars). The number of colony-forming units (CFU) was calculated using a conversion factor of $1.12 \times 10^{9} \mathrm{CFU} / \mathrm{Abs}_{600}$. No sugar: no added carbon source. Data represent mean \pm standard deviation from at least 10 independent experiments for biofilm and from at least 4 independent experiments for cell density. The mean values showing a statistically significant difference in comparison with the control value of 'No sugar' were denoted by * $(p<0.05)$.

tested carbon sources at the same concentration. Sucrose, cellobiose, and glucose supported cell growth, generating a cell density of more than $2 \times 10^{9} \mathrm{CFU} / \mathrm{ml}$, and biofilm formation under these conditions was comparable to the original XOM2 medium containing xylose. In contrast, maltose, fructose, and mannitol did not support cell growth, and the biofilm formation was similar to that in XOM2 medium with no carbon source. Interestingly, lactose significantly inhibited both cell growth and biofilm formation. Among the carbon sources tested, glucose elicited maximum cell density and biofilm formation. This result showed that biofilm formation was positively correlated with cell growth as a function of the available carbon source. Therefore, this observation, presented in Fig. 2, contradicted the inverse correlation between the cell density and biofilm formation shown in Fig. 1 .

\section{Effect of Nitrogen Source on Biofilm Formation}

Since the carbon source test did not show an inverse correlation between cell growth and biofilm formation, as presented in Fig. 1, the nitrogen sources were subsequently tested (Fig. 3). In the XOM2 medium, L-methionine $(670 \mu \mathrm{M})$ and sodium L-(+)-glutamate monohydrate $(10 \mathrm{mM})$ were replaced with the nitrogen sources of the four nutrient-rich
A

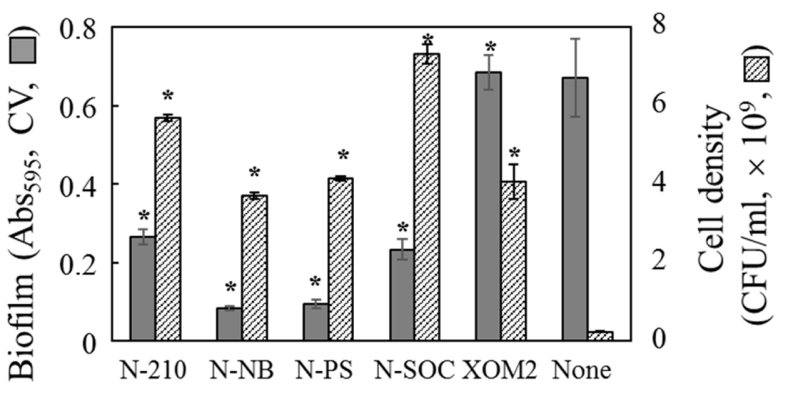

Nitrogen source

B

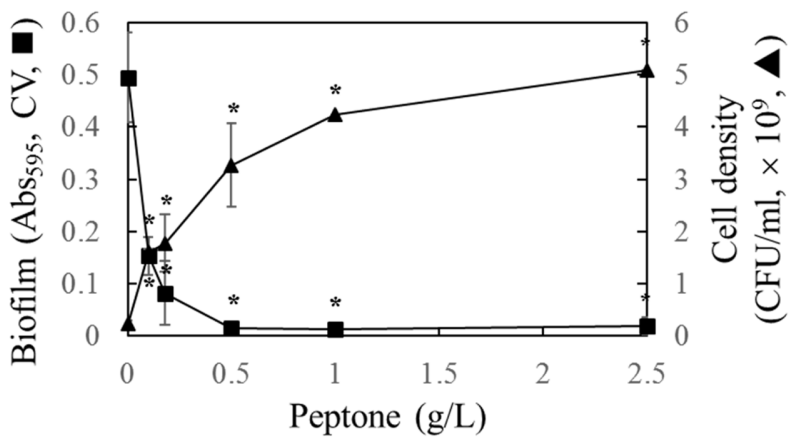

Fig. 3. Effect of nitrogen sources on Xoo biofilm formation and cell growth.

(A) Effect of nitrogen source on Xoo biofilm formation (solid bars) and cell growth (hatched bars). Cells were incubated in 96-well polyvinyl chloride microplates for $24 \mathrm{~h}$ with XOM2 medium in which L-methionine and sodium L-(+)-glutamate monohydrate were replaced with the indicated nitrogen sources. $\mathrm{N}-210: 8 \mathrm{~g} / 1$ casein hydrolysate and $4 \mathrm{~g} / \mathrm{l}$ yeast extract, N-NB: $3 \mathrm{~g} / 1$ beef extract and $5 \mathrm{~g} /$ 1 peptone, N-PS: $10 \mathrm{~g} / 1$ bacto-peptone, N-SOC: $20 \mathrm{~g} / 1$ tryptone and $5 \mathrm{~g} / 1$ yeast extract, XOM2: XOM2 medium alone, None: XOM medium without nitrogen sources. The cell growth was measured independently by culturing cells in test tubes (hatched bars). After measuring $\mathrm{Abs}_{600}$, the number of colony-forming units (CFU) was calculated using a conversion factor of $1.12 \times 10^{9} \mathrm{CFU} / \mathrm{Abs}_{600}$. The mean values showing a statistically significant difference in comparison with the control value of 'None' were denoted by * $(p<$ 0.05). (B) Effect of peptone on Xoo biofilm formation ( $\mathbf{\square})$ and cell growth $(\mathbf{\Lambda})$. L-methionine and sodium L-(+)-glutamate monohydrate in XOM2 medium were replaced with peptone at the same concentration. Data represent mean \pm standard deviation from at least 5 independent experiments for biofilm and from 2 independent experiments for cell density. The mean values showing a statistically significant difference in comparison with the control value at $0 \mathrm{~g} / 1$ were denoted by * $(p<0.05)$.

media tested. The tested nitrogen sources were $8.0 \mathrm{~g} / 1$ casein hydrolysate and $4.0 \mathrm{~g} / 1$ yeast extract from 210 medium (N-210 in Fig. 3A), $3.0 \mathrm{~g} / \mathrm{l}$ beef extract and $5.0 \mathrm{~g} / \mathrm{l}$ 
peptone from nutrient broth (N-NB in Fig. 3A), $10.0 \mathrm{~g} / 1$ peptone and $1.0 \mathrm{~g} / 1$ monosodium glutamate from PS medium (N-PS in Fig. 3A), and $20.0 \mathrm{~g} / 1$ tryptone and $5.0 \mathrm{~g} / 1$ yeast extract from SOC medium (N-SOC in Fig. $3 \mathrm{~A}$ ). None of the XOM2 media with substituted nitrogen sources tested supported biofilm formation, but the cell growth remained at a similar or higher level when compared to the original XOM2 media (Fig. 3A). These results are consistent with the inverse correlation between cell growth and biofilm formation shown in Fig. 1.

Decreased biofilm formation was observed with nitrogen sources from nutrient broth and PS medium, and their common nitrogen source was peptone. Thus, to confirm the inverse correlation between biofilm formation and the available nitrogen sources, the concentration-dependent inhibition of biofilm formation was evaluated using peptone (Fig. 3B). Cells grew better as the peptone concentration increased, and less biofilm was formed. This result confirmed that biofilm formation was inhibited by the nitrogen source; both carbon and nitrogen sources supported the cell growth, but only nitrogen sources inhibited biofilm formation by Xoo.

\section{Effect of Amino Acids and Ammonium Nitrate on Biofilm Formation}

The nitrogen sources tested in Fig. 3 were made primarily with amino acids. Hence, the effect of each amino acid on Xoo biofilm formation was evaluated (Fig. 4). Of the 19 amino acids tested at $50 \mathrm{mM}, 10$ amino acids reduced biofilm formation by over $40 \%$ (Fig. 4A). At $100 \mathrm{mM}, 12$ of the 18 amino acids tested inhibited biofilm formation by over 68\% (Fig. 4B) (100 mM tyrosine and tryptophan were not tested because of their poor solubility). Only five amino acids (arginine, aspartic acid, glutamic acid, lysine, and proline) supported cell growth at $100 \mathrm{mM}$ (Fig. S2). These results showed that single amino acids were sufficient to inhibit Xoo biofilm formation.

The effect of ammonium nitrate on Xoo biofilm was also evaluated (Fig. 5). Like most amino acids, ammonium nitrate inhibited both biofilm formation and cell growth.

\section{Biofilm Formation in Rice Sap Condition}

In rice, Xoo forms a biofilm in the xylem rather than the phloem [23, 24]. We examined whether the preferential formation of Xoo biofilms in the xylem may be determined by the amino acids in rice (Fig. 6). To simulate the amino acid composition of xylem [32] and phloem [33] saps, L-methionine $(670 \mu \mathrm{M})$ and sodium L-(+)-glutamate monohydrate $(10 \mathrm{mM})$ were substituted in the XOM2
A

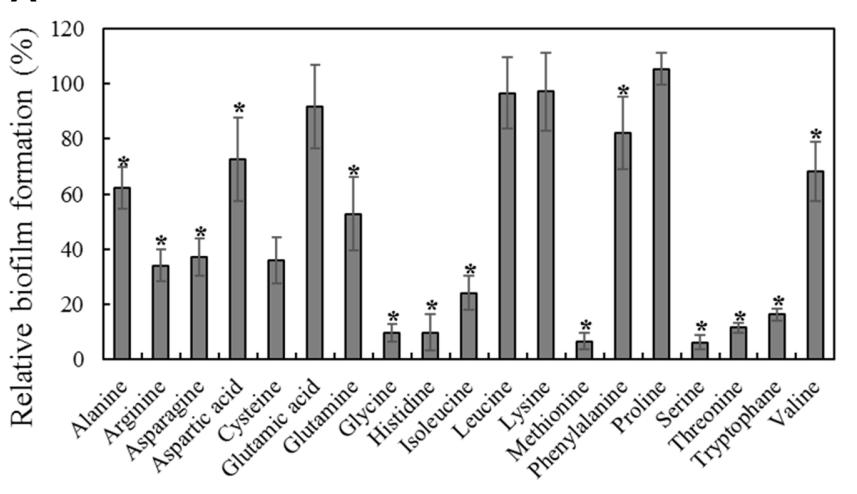

B

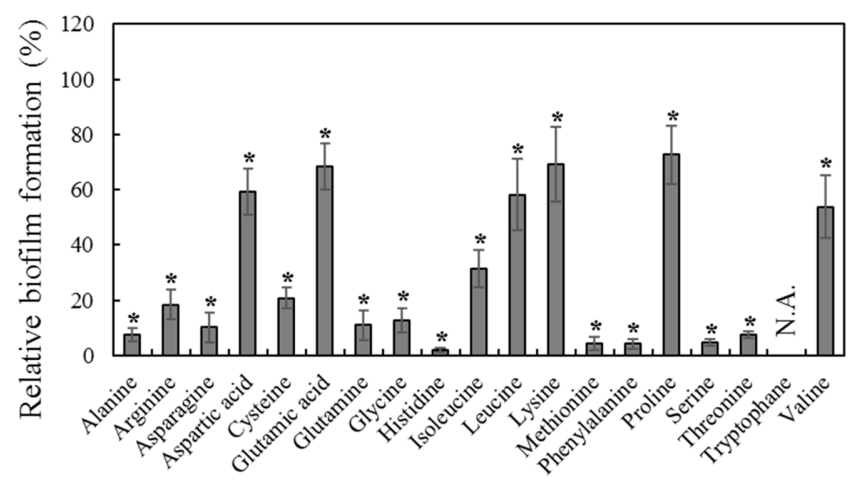

Fig. 4. Effect of amino acids on Xoo biofilm formation. Cells were incubated in 96-well polyvinyl chloride microplates for $24 \mathrm{~h}$ with XOM2 medium in which L-methionine and sodium L-(+)glutamate monohydrate were replaced with the indicated amino acid. Amino acids at $50 \mathrm{mM} \mathrm{(A)} \mathrm{and} 100 \mathrm{mM}$ (B) were tested. Biofilms were quantified using crystal violet ( $\mathrm{CV}$ in the $\mathrm{y}$-axis label). Data represent mean \pm standard deviation from at least 5 independent experiments, except for proline, which was used in 3 independent experiments. The mean values showing a statistically significant difference in comparison with the control value without amino acid were denoted by * $(p<0.05)$.

medium. The amino acid composition of xylem sap (A.A. in xylem in Fig. 6) supported increased biofilm formation compared with the XOM2 medium (Fig. 6A), but reduced cell growth (Fig. 6B). However, the amino acid composition of phloem sap (A.A. in phloem in Fig. 6) showed the opposite effects, inhibiting biofilm formation (Fig. 6A) and supporting cell growth comparable to that in the XOM2 medium (Fig. 6B).

\section{Discussion}

Increased bacteria cell growth usually supports increased biofilm formation. However, biofilm formation by Xoo 

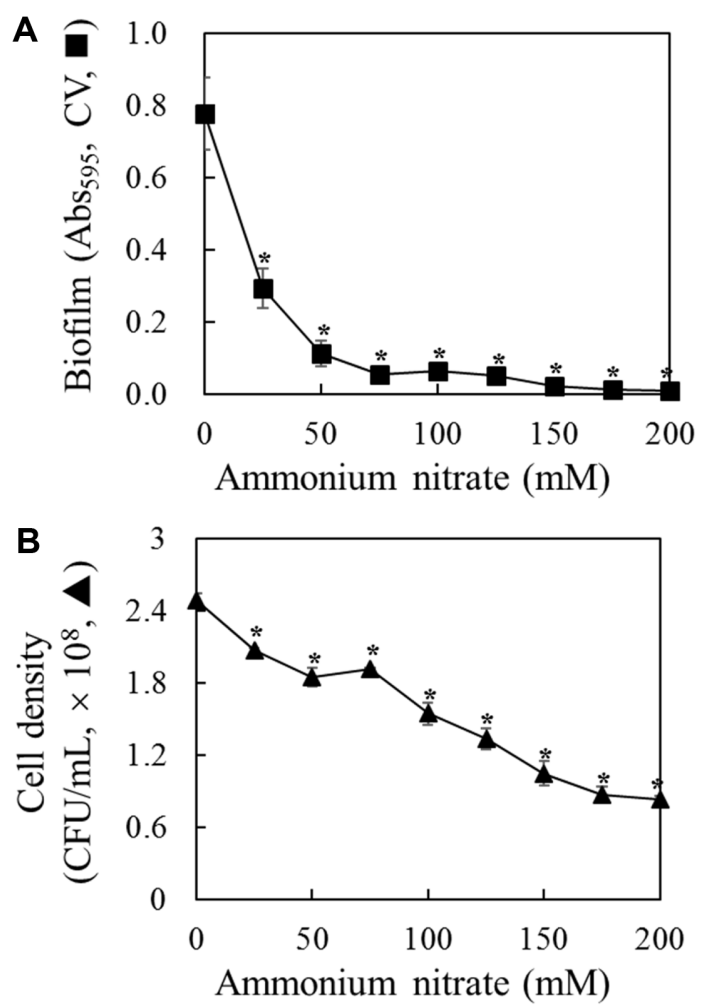

Fig. 5. Effect of ammonium nitrate on Xoo biofilm formation (A) and cell growth (B).

Cells were incubated in 96-well polyvinyl chloride microplates for $24 \mathrm{~h}$ with XOM2 medium in which L-methionine and sodium L-(+)glutamate monohydrate were replaced with ammonium nitrate. Biofilms were quantified using crystal violet (CV in the y-axis label;

口). Cell growth was measured independently by culturing cells in test tubes. The number of colony-forming units (CFU) was calculated using a conversion factor of $1.12 \times 10^{9} \mathrm{CFU} / \mathrm{Abs}_{600}(\boldsymbol{\Delta})$. Data represent mean \pm standard deviation from 10 independent experiments for biofilm and from 2 independent experiments for cell density. The mean values showing a statistically significant difference in comparison with the control value at $0 \mathrm{mM}$ were denoted by * $(p<0.05)$.

increased in minimal defined media more so than in complex media, which favored cell growth. This inverse correlation between biofilm formation and cell growth suggested the existence of strong negative effectors of biofilm formation among the nutrient components in the complex media. The presence of a nitrogen source inhibited biofilm formation (Fig. 3) unlike the presence of carbon sources (Fig. 2). These results showed that the inhibitory effect of nitrogen sources on biofilm formation was enhanced by increasing concentration, regardless of cell growth. Additional experiments in the present study showed that environmental conditions, such as $\mathrm{pH}$, temperature, and
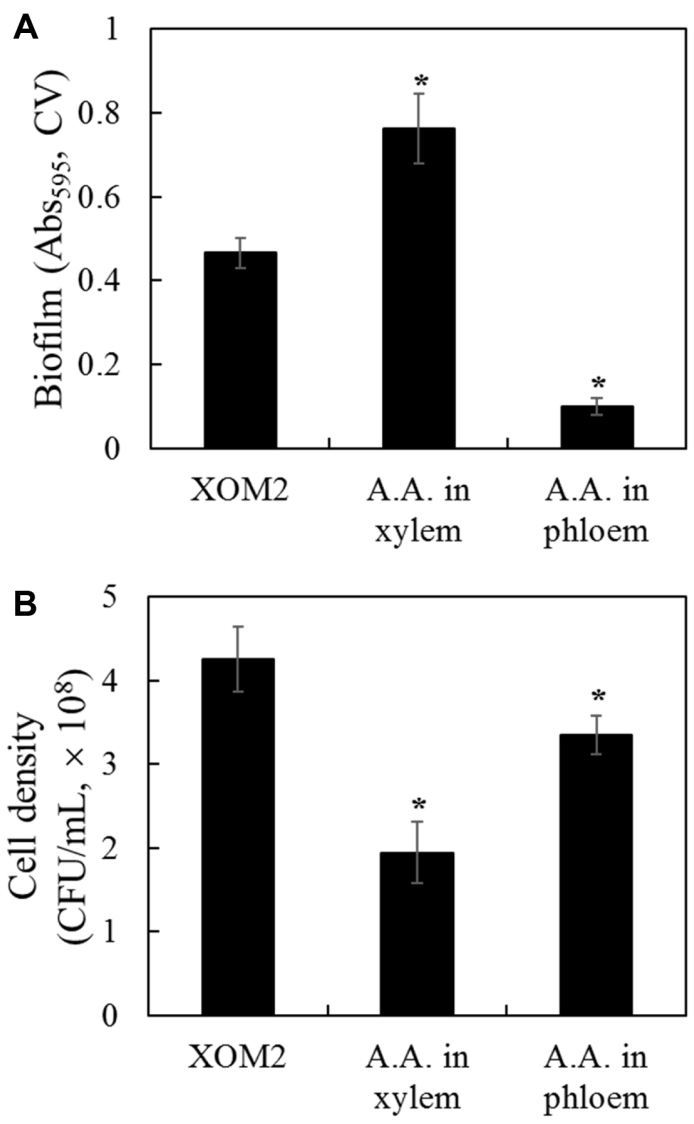

Fig. 6. Effect of the amino acid composition of xylem and phloem saps on Xoo biofilm formation (A) and cell growth (B).

The amino acid mixtures, which were prepared according to previous studies on xylem sap (shown as A.A. in xylem) and phloem sap (shown as A.A. in phloem), substituted the equivalent amino acids in the XOM2 medium. Data represent mean \pm standard deviation from at least 6 independent experiments. The mean values showing a statistically significant difference in comparison with the control value of XOM2 medium were denoted by * $(p<0.05)$.

salt, do not contribute to the inverse correlation between cell growth and biofilm formation (Fig. S3).

Amino acids inhibit biofilm formation in several bacteria. Previous studies have suggested that arginine inhibits biofilm formation by Streptococcus mutans [20, 35], S. gordonii [36], and oral bacterial communities [37, 38]. Other studies have suggested that glycine inhibits the biofilm formation of bacterial communities [39], and methionine and tryptophan inhibit biofilm formation by Pseudomonas aeruginosa [40, 41]. In addition, nitrite, which is an inorganic nitrogen source, has been shown to inhibit biofilm formation by Staphylococcus aureus and S. epidermidis [42]. 
Xoo produced a biofilm and blocked the plant vascular system $[23,24]$, which is one of the pathogenic mechanisms of Xoo [43]. The majority of the Xoo biofilm was detected in the xylem of rice leaves [23, 24]. The xylem sap of rice provides favorable conditions for biofilm formation by Xoo, with a concentration of $1 \mathrm{mM}$ or less of each amino acid [32]. The limited cell growth of Xoo in xylem vessels [19] suggests that xylem sap is a nutrient-limited medium for Xoo. However, the phloem sap of rice is not an ideal medium for biofilm formation by Xoo because it contains 3-8\% amino acids [33]. Our experimental results, presented in Fig. 6, showed that amino acids may be an important factor influencing biofilm formation by Xoo in xylem rather than phloem.

Exopolysaccharide is an important determinant of biofilm formation [44], and the exopolysaccharide of Xoo is an important virulence factor [45, 46]. When Xoo was treated with thyme oil, its exopolysaccharide production, biofilm formation, and virulence were simultaneously reduced [47]. We observed that XOM2 medium supported the production of exopolysaccharide, but PS medium did not (Fig. S4). This result confirmed the strong relationship between exopolysaccharide production and biofilm formation. Moreover, it suggests that the xylem sap of rice may promote the formation of Xoo exopolysaccharide, while the phloem sap may not. This inference may also provide an explanation of why Xoo selectively forms biofilms in xylem vessels. The results of the present study predict biofilm formation by Xoo in xylem sap as a result of nutritional conditions, excluding interaction with the host.

Among the cultivars of rice, some are resistant to Xoo pathogenesis, while others are susceptible. Resistance in rice cultivars was associated with the flow in the xylem vessel after infection, while Xoo formed a biofilm mass in the xylem vessel of the susceptible cultivars after infection [23]. Based on the results of the present study, differences between the nutritional compositions of the xylem sap of rice cultivars resistant to Xoo pathogenesis and those of rice cultivars susceptible to Xoo will confirm the importance of nutritional composition in the xylem sap for bacterial blight.

Rice paddies also provide an ideal environment for biofilm formation by Xoo because they provide limited nutrients [48]. This observation supports the hypothesis that the rice paddy and other natural environments are the origin of Xoo infection.

Based on the conditions that promote the formation of Xoo biofilms, the results of the present study suggest that the composition of the xylem sap and the natural habitat of rice are suitable for biofilm formation by this pathogen.
This suggestion is consistent with the location of X. oryzae found in previous studies [19].

\section{Acknowledgments}

This work was carried out with the support of "Cooperative Research Program for Agriculture Science and Technology Development (Project No. PJ013896032018)" Rural Development Administration, Republic of Korea.

\section{Conflict of Interest}

The authors have no financial conflicts of interest to declare.

\section{References}

1. Swings J, Van Den Mooter M, Vauterin L, Hoste B, Gillis M, Mew TW, et al. 1990. Reclassification of the causal agents of bacterial blight (Xanthomonas campestris pv. oryzae) and bacterial leaf streak (Xanthomonas campestris pv. Oryzicola) of rice as pathovars of Xanthomonas oryzae (ex ishiyama 1922) sp. Nov., nom. Rev. Int. J. Syst. Bacteriol. 40: 309-311.

2. Adhikari TB, Mew TW, Teng PS. 1994. Progress of bacterial blight on rice cultivars carrying different $x a$ genes for resistance in the field. Plant Dis. 78: 73-77.

3. Durgapal JC. 1985. Self-sown plants from bacterial blightinfected rice seeds - a possible source of primary infection in northwest india. Curr. Sci. India 54: 1283-1284.

4. Devadath S, Dath AP. 1985. Infected chaff as a source of inoculum of Xanthomonas campestris pv. oryzae to the rice crop. J. Plant Dis. Protect. 92: 485-488.

5. Hsieh SPY, Buddenhagen IW, Kauffman HE. 1974. An improved method for detecting the presence of Xanthomonas oryzae in rice seed. Phytopathology 64: 273-274.

6. Murty VST, Devadath S. 1984. Role of seed in survival and transmission of Xanthomonas campestris pv. oryzae causing bacterial blight of rice. J. Phytopathol. 110: 15-19.

7. Mew TW, Unnamalai N, Baraoidan MR. 1989. Presented at the Bacterial Blight of Rice, Proceedings of the International Workshop on Bacterial Blight of Rice, Manila, Philippines, March 14-18, 1988.

8. Singh RN. 1971. Perpetuation of bacterial blight disease of paddy and preservation of its incitant. Ii. Survival of Xanthomonas oryzae in soil. Indian Phytopathol. 24: 153-154.

9. Murty VST, Devadath S. 1982. Survival of Xanthomonas campestris pv. oryzae in different soils. Indian Phytopathol. 35: 32-38.

10. Stoodley P, Sauer K, Davies DG, Costerton JW. 2002. Biofilms as complex differentiated communities. Annu. Rev. Microbiol. 56: 187-209.

11. Donlan RM, Costerton JW. 2002. Biofilms: survival mechanisms 
of clinically relevant microorganisms. Clin. Microbiol. Rev. 15: 167-193.

12. Valerie NDG, Natalie V, Maarten F, Cyrielle IK, Aline MV, Serge B, et al. 2009. Novel persistence genes in Pseudomonas aeruginosa identified by high-throughput screening. FEMS Microbiol. Lett. 297: 73-79.

13. Souza AA, Takita MA, Coletta-Filho HD, Caldana C, Yanai $\mathrm{GM}$, Muto NH, et al. 2004. Gene expression profile of the plant pathogen Xylella fastidiosa during biofilm formation in vitro. FEMS Microbiol. Lett. 237: 341-353.

14. Lim SH, So BH, Wang JC, Song ES, Park YJ, Lee BM, et al. 2008. Functional analysis of pilq gene in Xanthomanas oryzae pv. oryzae, bacterial blight pathogen of rice. J. Microbiol. 46: 214-220.

15. Pradhan BB, Ranjan M, Chatterjee S. 2012. Xadm, a novel adhesin of Xanthomonas oryzae pv. oryzae, exhibits similarity to rhs family proteins and is required for optimum attachment, biofilm formation, and virulence. Mol. Plant Microbe In. 25: 1157-1170.

16. Su J, Zou X, Huang L, Bai T, Liu S, Yuan M, et al. 2016. DgcA, a diguanylate cyclase from Xanthomonas oryzae pv. oryzae regulates bacterial pathogenicity on rice. Sci. Rep.-UK 6: 25978

17. Crutis LC. 1943. Deleterious effects of guttated fluid on foliage. Am. J. Bot. 30: 778-781.

18. Ou SH. 1985. Rice disease. Commonwealth Agricultural Bureau, Kew, Surrey, England.

19. Noda T, Kaku H. 1999. Growth of Xanthomonas oryzae pv. oryzae in planta and in guttation fluid of rice. Ann. Phytopathol. Soc. Jpn. 65: 9-14.

20. Grewal RK, Gupta S, Das S. 2012. Xanthomonas oryzae pv oryzae triggers immediate transcriptomic modulations in rice. BMC Genomics 13: 49.

21. Hilaire E, Young SA, Willard LH, McGee JD, Sweat T, Chittoor JM, et al. 2001. Vascular defense responses in rice: Peroxidase accumulation in xylem parenchyma cells and xylem wall thickening. Mol. Plant Microbe. Interact. 14: 14111419.

22. Young SA, Guo A, Guikema JA, White FF, Leach JE. 1995. Rice cationic peroxidase accumulates in xylem vessels during incompatible interactions with Xanthomonas oryzae pv oryzae. Plant Physiol. 107: 1333-1341.

23. Han SW, Park CJ, Lee SW, Ronald P. 2008. An efficient method for visualization and growth of fluorescent Xanthomonas oryzae pv. oryzae in planta. BMC Microbiol. 8: 164.

24. Mew TW, Alvarez AM, Leach JE, Swings J. 1993. Focus on bacterial blight of rice. Plant Dis. 77: 5-12.

25. Lee BM, Park YJ, Park DS, Kang HW, Kim JG, Song ES, et al. 2005. The genome sequence of Xanthomonas oryzae pathovar oryzae KACC10331, the bacterial blight pathogen of rice. Nucl. Acids Res. 33: 577-586.

26. Kim HS, Park HJ, Heu S, Jung J. 2004. Molecular and functional characterization of a unique sucrose hydrolase from Xanthomonas axonopodis pv. Glycines. J. Bacteriol. 186: 411-418.

27. Shaw JJ, Dane F, Geiger D, Kloepper JW. 1992. Use of bioluminescence for detection of genetically engineered microorganisms released into the environment. Appl. Environ. Microbiol. 58: 267-273.

28. Myung IS, Cho Y, Lee YH, Kwon HM. 2001. Phage typing and lysotype distribution of Xanthomonas axonopodis pv. Citri, the causal agent of citrus bacterial canker in Korea. Plant Pathol. J. 17: 336-341.

29. Miller JH. 1972. Experiments in molecular genetics. Cold Spring Harbor Laboratory, Cold Spring Harbor, NY, USA.

30. Tsuge S, Furutani A, Fukunaka R, Oku T, Tsuno K, Ochiai H, et al. 2002. Expression of Xanthomonas oryzae pv. oryzae hrp genes in XOM2, a novel synthetic medium. J. Gen. Plant Pathol. 68: 363-371.

31. Ryan RP, Fouhy Y, Lucey JF, Jiang B-L, He Y-Q, Feng J-X, et al. 2007. Cyclic di-GMP signalling in the virulence and environmental adaptation of Xanthomonas campestris. Mol. Microbiol. 63: 429-442.

32. Bailey KJ, Leegood RC. 2016. Nitrogen recycling from the xylem in rice leaves: Dependence upon metabolism and associated changes in xylem hydraulics. J. Exp. Bot. 67: 29012911.

33. Fukumorita T, Chino M. 1982. Sugar, amino acid and inorganic contents in rice phloem sap. Plant Cell Physiol. 23: 273-283.

34. Kim TJ, Young BM, Young GM. 2008. Effect of flagellar mutations on Yersinia enterocolitica biofilm formation. Appl. Environ. Microbiol. 74: 5466-5474.

35. Sharma S, Lavender S, Woo J, Guo L, Shi W, KilpatrickLiverman L, et al. 2014. Nanoscale characterization of effect of L-arginine on Streptococcus mutans biofilm adhesion by atomic force microscopy. Microbiology 160: 1466-1473.

36. Jakubovics NS, Robinson JC, Samarian DS, Kolderman E, Yassin SA, Bettampadi D, et al. 2015. Critical roles of arginine in growth and biofilm development by Streptococcus gordonii. Mol. Microbiol. 97: 281-300.

37. Nascimento MM, Browngardt C, Xiaohui X, Klepac-Ceraj V, Paster BJ, Burne RA. 2014. The effect of arginine on oral biofilm communities. Mol. Oral Microbiol. 29: 45-54.

38. Tada A, Nakayama-Imaohji H, Yamasaki H, Hasibul K, Yoneda S, Uchida K, et al. 2016. Cleansing effect of acidic L-arginine on human oral biofilm. BMC Oral Health 16: 40.

39. John G, Becker J, Schwarz F. 2016. Effectivity of air-abrasive powder based on glycine and tricalcium phosphate in removal of initial biofilm on titanium and zirconium oxide surfaces in an ex vivo model. Clin. Oral Invest. 20: 711-719.

40. Gnanadhas DP, Elango M, Datey A, Chakravortty D. 2015. Chronic lung infection by Pseudomonas aeruginosa biofilm is cured by L-methionine in combination with antibiotic therapy. Sci. Rep.-UK 5: 16043. 
41. Brandenburg KS, Rodriguez KJ, McAnulty JF, Murphy CJ, Abbott NL, Schurr MJ, et al. 2013. Tryptophan inhibits biofilm formation by Pseudomonas aeruginosa. Antimicrob. Agents Ch. 57: 1921-1925.

42. Schlag S, Nerz C, Birkenstock TA, Altenberend F, Götz F. 2007. Inhibition of staphylococcal biofilm formation by nitrite. J. Bacteriol. 189: 7911-7919.

43. Meng Y, Li Y, Galvani CD, Hao G, Turner JN, Burr TJ, et al. 2005. Upstream migration of Xylella fastidiosa via pilusdriven twitching motility. J. Bacteriol. 187: 5560-5567.

44. Vu B, Chen M, Crawford R, Ivanova E. 2009. Bacterial extracellular polysaccharides involved in biofilm formation. Molecules. 14: 2535-2554.

45. Dharmapuri S, Sonti RV. 1999. A transposon insertion in the gumg homologue of Xanthomonas oryzae pv. oryzae causes loss of extracellular polysaccharide production and virulence. FEMS Microbiol. Lett. 179: 53-59.

46. Singh VB, Kumar A, Isaac Kirubakaran S, Ayyadurai N, Sunish Kumar R, Sakthivel N. 2006. Comparison of exopolysaccharides produced by Xanthomonas oryzae pv. oryzae strains, $\mathrm{BXO} 1$ and $\mathrm{BXO} 8$ that show varying degrees of virulence in rice (Oryza sativa L.). J. Phytopathol. 154: 410413.

47. Singh A, Gupta R, Tandon S, Pandey R. 2017. Thyme oil reduces biofilm formation and impairs virulence of Xanthomonas oryzae. Front. Microbiol. 8: 1074.

48. Doi R, Ranamukhaarachchi SL. 2009. Correlations between soil microbial and physicochemical variations in a rice paddy: implications for assessing soil health. J. Biosci. 34: 969-976. 